\title{
DESIGN AEROESPACIAL: Aeronave de defesa social
}

\author{
Aerospace Design: Social Defense Aircraft
}

AMARAL, Marina; Graduanda em Design; Universidade Federal do Rio Grande do Norte marinaamaral02@gmail.com

FLOR, Gabriela; Bacharel em Design; Universidade Federal do Rio Grande do Norte gabrielaflorrm@gmail.com

LINCOLN, Dino; PhD- Professor; Universidade Federal do Rio Grande do Norte dinolincoln@gmail.com

SANTAROSA, José Guilherme; PhD - Professor; Universidade Federal do Rio Grande do Norte jguilhermesantarosa@gmail.com

\section{Resumo}

Em uma época a qual a vulnerabilidade feminina está tomando espaço nas discussões e políticas de enfrentamento à violência contra a mulher tomam prioridade em instituições de ensino, concebese o projeto AEDES (Aeronave de Defesa Social). O presente artigo apresenta o processo de design deste VANT (Veículo Aéreo Não-Tripulado) projetado por estudantes do bacharelado em design da UFRN (Universidade Federal do Rio Grande do Norte). Com o objetivo de patrulhar alunas circulando em áreas que as mesmas considerem de risco, o projeto seguiu uma metodologia interdisciplinar, desde a exploração do problema à apresentação de um protótipo. Após o processo, conforme descrito neste documento, o design de um VANT leve do tipo VTOL (Vertical Take-Off and Landing) fora apresentado para atender a demanda de proteção das alunas circulando no campus da UFRN.

Palavras Chave: VTOL; VANT; Social, Aeronave, Design.

\begin{abstract}
At a time when women's vulnerability is taking place in the discussions and policies to combat violence against women is given priority to educational institutions, the AEDES (Social Defense Aircraft) project is conceived. The present article presents the design process of this UAV (Unmanned Aerial Vehicle) project by students of the UFRN (Federal University of Rio Grande do Norte) bachelor of design. With the aim of patrolling students in areas that they consider of risk, the project followed an interdisciplinary methodology, from the exploration of the problem to the presentation of a prototype. After the process, as described in this document, the design of a lightweight VTOL (Vertical Take-Off and Landing) type VANT was presented to meet the protection demand of the students around the UFRN campus.
\end{abstract}

Keywords: VTOL, UAV, Social, Aircraft, Design. 


\section{Introdução}

O combate a insegurança nas universidades públicas é um tema com crescente demanda. Segundo dados da Secretaria de Segurança Pública do Estado de São Paulo (SSP), o número de roubos próximo a Universidade de São Carlos aumentou quase 43\% entre abril de 2016 e 2017 (Silveira,2017). A Universidade Federal do Rio Grande do Norte (UFRN) também vem sofrendo com a insegurança, só no ano de 2017 foram registrados 21 assaltos em seu campus, sendo as paradas de ônibus os pontos mais visados pelos bandidos, segundo informação cedida pela Diretoria de Segurança Patrimonial (DSP) da instituição de ensino em abril de 2017. Especialistas em segurança pública apontam os universitários como um bom alvo para os bandidos já que muitas vezes esses possuem objetos de valor como computadores e celulares (SILVEIRA, 2017).

Concomitantemente, casos de violência contra mulher estão sendo registrados diariamente no Brasil. Estima-se que $67 \%$ das mulheres já sofreram algum tipo de assédio sexual em ambiente universitário (Avon et al., 2015). Dados como estes destacam a vulnerabilidade feminina em instituições acadêmicas e a necessidade de uma ferramenta de defesa e segurança.

Dessa forma foi proposto durante a disciplina de Projeto de Produto $\mathrm{V}$, do curso de Bacharelado em Design da UFRN, o desenvolvimento de um veículo aéreo não-tripulado para vigilância da universidade, com a missão primária de proteger alunas circulando em áreas de risco do campus. A aeronave deveria ser equipada com uma câmera tipo FLIR (Forward Looking Infrared) e orbitaria sobre as alunas que solicitassem proteção através de um aplicativo em seu smartphone.

Os veículos aéreos não tripulados (VANT) em inglês Unmanned Aerial Vehicles/Systems (UAV), também conhecidos como drones, são comumente utilizados em serviços militares devido a sua eficácia em realizar missões consideradas de risco, sem que seja colocada a vida humana em perigo (MILESKI, 2007). Contudo, com os avanços tecnológicos dos últimos anos, o número de drones utilizados para fins de uso civil como, mapeamento, vigilância, agricultura e delivery vem crescendo. No Brasil, o projeto que buscava regulamentar o uso de drones na segurança pública foi aprovado em decisão final, em 06/12/2017, pela Comissão de Constituição, Justiça e Cidadania (Agência Senado, 2017). Na cidade de São Paulo, uma iniciativa promovida pela Secretaria Municipal de Segurança Urbana, apresentou um novo projeto de segurança através do uso de drones para o monitoramento e operações específicas de vigilância na cidade (Prefeitura de São Paulo, 2017).

Segundo Silva Neto (1989), as operações aéreas de segurança pública podem ser divididas em duas áreas, a primeira são as operações aero terrestres, que utilizam aeronaves de asa fixa para efetuar o seu transporte até a área de risco e a segunda são as operações helitransportadas, realizadas com aeronaves de asas rotativas, esse tipo de operação possui uma abordagem mais ostensiva, de acordo com o autor, e tem o objetivo de inibir e prevenir ocorrências que infrinjam a ordem pública. A partir de todos os dados coletados foi possível identificar algumas questões que foram consideradas nas propostas de solução do problema e apresentadas em "métodos e técnicas".

\section{Processo De Design}

Para a realização do projeto foi necessário estudo avançado em alguns tópicos fundamentais para o desenvolvimento do mesmo. Durante o estudo foram discutidos assuntos voltados para ciência, tecnologia e metodologia de projeto, conteúdos esses relevantes para a criação do VANT. Ainda com o intuito de detalhar os estudos, visitas técnicas foram realizadas à centros de 
inteligência aeroespacial:

- Centro de Lançamento Barreira do Inferno (CLBI), braço do Departamento de Ciência e Tecnologia Aeroespacial (DCTA),

- Esquadrão Gavião e Esquadrão Joker - Base Aérea de Natal - ALA 10,

- Car-Kará Aerodesign - CT / UFRN;

- Como também ao PROTOLAB - IMD / UFRN - Laboratório de Prototipagem.

Em seguida, uma maior exploração da problemática foi realizada, com o propósito de aprofundar as reais condições da violência em âmbito universitário, bem como a vulnerabilidade feminina em ambientes sociais e acadêmicos, além de estudar o território da UFRN e suas possíveis áreas de risco.

Após a fase de fundamentação teórica e pesquisa de campo, iniciou-se efetivamente a etapa de projeto de produto na qual propostas de soluções foram geradas por meio de sketchs - o conceito que melhor se adequou aos requisitos foi escolhido e detalhado no desenho técnico e modelagem 3D. Além disso, verificações aerodinâmicas foram realizadas digitalmente utilizando a ferramenta Flow Design, que simula um túnel de vento virtual, e também através de uma análise física utilizando o modelo reduzido do VANT impresso em 3D e um túnel de vento. Posteriormente o modelo em escala $1 / 1$ foi construído em isopor. Todo esse trabalho foi apresentado em uma exposição realizada na UFRN para convidados especialistas militares e civis.

A seguir, cada uma destas etapas de concepção do VANT AEDES é delineada em maiores detalhes.

\subsection{Estudos avançados em Ciência e Tecnologia Aeroespacial.}

Durante essa etapa fez necessário um estudo aprofundado de temas relevantes para a concepção da solução, dividindo-se em três conteúdos: ciência, tecnologia e projeto.

No estudo da ciência aeroespacial, os conteúdos focados foram: pressão atmosférica, aerodinâmica e física aplicada. Tópicos fundamentais para compreender como uma aeronave se relaciona com a natureza.

$\mathrm{Na}$ etapa da tecnologia, o cerne de estudo foi, especificidades físicas das aeronaves. Portanto, estudou-se sobre suas estruturas, motores, e as tipologias de aeronaves existentes hoje em dia. Este conteúdo guiou a posterior criação do VANT.

Já a etapa de projeto, no qual o designer entra com seu conhecimento de desenvolvimento de projeto, todos os conteúdos foram relacionados e uma solução-modelo foi projetada. No entanto se fez necessário a revisão de alguns conteúdos como: criação de conceito, projeto de cockpits e prototipagem.

Ainda com o propósito de aprofundar o conhecimento sobre Ciência e Tecnologia Aeroespacial, visitas técnicas foram realizadas à centros especializados em conteúdos Aeroespacial.

O primeiro local visitado foi o Centro de Lançamento Barreira do Inferno (CLBI), uma instituição do Comando da Aeronáutica e do Departamento de Ciência e Tecnologia Aeroespacial (DCTA) em Natal-RN (Fig.1).

O DCTA é responsável pelo desenvolvimento de soluções científico-tecnológicas, no campo 
aeroespacial. E utiliza dos pilares ensino, pesquisa, desenvolvimento, inovação e serviços técnicos especializados para a realização de projetos avançados e de valor estratégico para a nação. Dentro do DCTA foram desenvolvidos importantes projetos para a sociedade brasileira, como o motor a álcool e a urna eletrônica.

O CLBI é um centro de lançamento que tem o propósito de executar e apoiar atividades relacionadas à lançamentos e rastreio de engenhos aeroespaciais, bem como processar dados de suas cargas úteis. Também objetiva contribuir para a execução de testes, experimentos, pesquisa básica ou aplicada e outras atividades de desenvolvimento tecnológico de interesse da Aeronáutica, relacionados com a Política da Aeronáutica para Pesquisa e Desenvolvimento e com a Política Nacional de Desenvolvimento das Atividades Espaciais.

Figura 1 - Visita Técnica à Barreira do Inferno

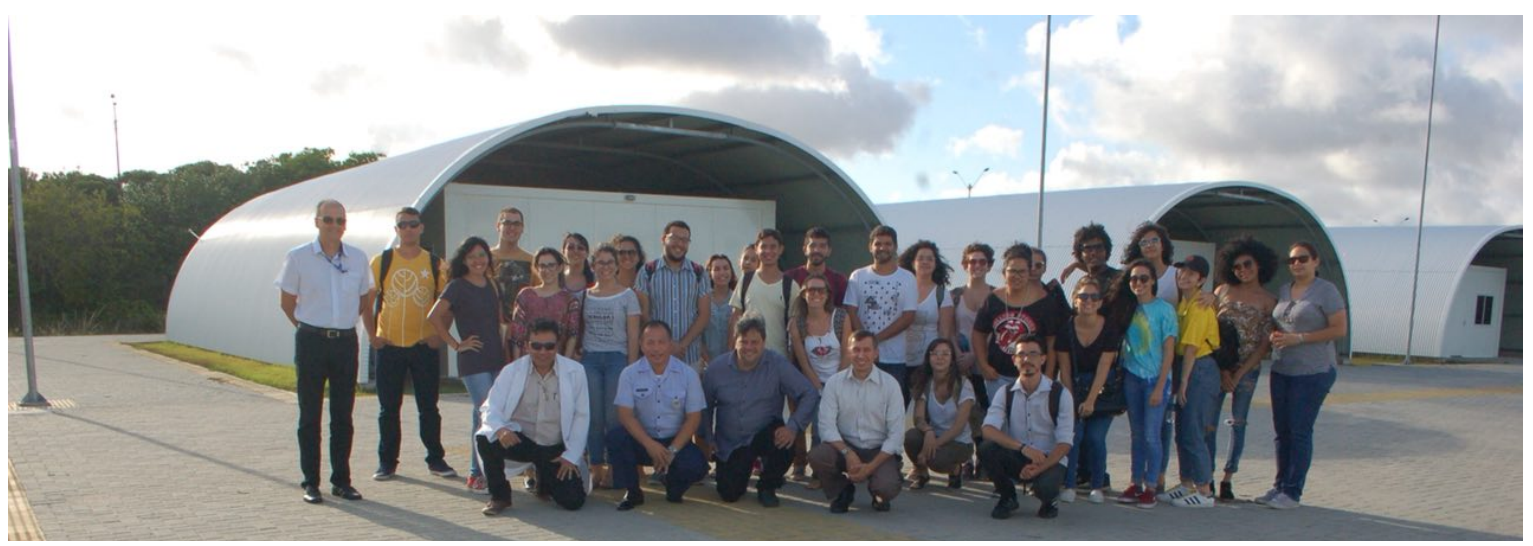

Fonte: AUTORES (2017)

Outra visita ocorreu na Base Aérea de Natal (BANT) ALA-10 (Fig.2), recepcionados pelos Esquadrão Gavião e Esquadrão Joker. Foi de grande importância para o conhecimento sobre tecnologia aeroespacial, pois caracterizou-se uma fase de imersão. Durante essa etapa foram realizadas discursões sobre mecanismos de aeronaves, como helicópteros e aviões de caça, foram abordados e conteúdos estudados em sala foram revisados de forma prática.

Figura 2 - Visita técnica à Base Aérea de Natal (BANT)

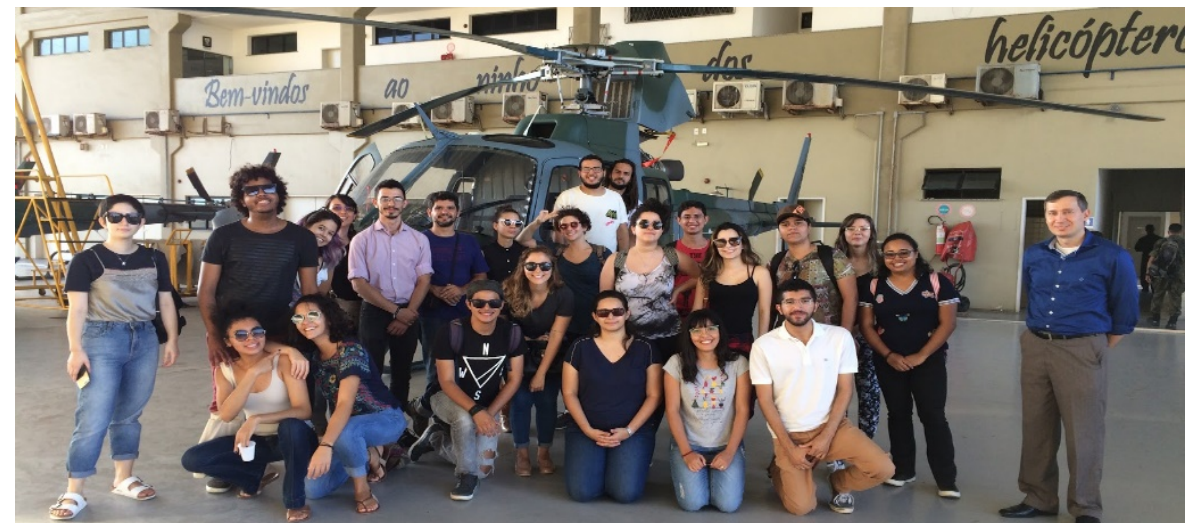

Fonte: Autores (2017) 
A visita à equipe Car-Kará Aerodesign - CT / UFRN também foi um ponto significante para um estudo detalhado pois, foi possível compartilhar informações com estudantes que trabalham na construção de aeronaves para competição. Com isso foi possível acompanhar parte do processo de construção de uma aeronave, conhecimento essencial para a fase de desenvolvimento de projeto.

O último local visitado foi o PROTOLAB Laboratório de Prototipagem da UFRN, nele o conhecimento de impressão 3D foi aprimorado e modelos foram impressos, o que contribuiu para o estudo de prototipagem através de um arquivo digital. Essa foi uma fase de grande importância para o desenvolvimento do projeto já que o processo de prototipagem é indispensável para a criação de um novo produto, pois evita o alto custo de correção de problemas em fases adiantadas do projeto (MACARRÃO, 2007).

\subsection{Exploração do problema}

Foi proposto através do briefing, o desenvolvimento de um veículo-aéreo não tripulado do tipo VTOL ou STOL, equipado com uma câmera tipo FLIR (Forward Looking Infrared), que deveria ser solicitado por alunas do campus, em situação de risco, via aplicativo em dispositivo móvel (smartphone). Portanto, primeiramente foi necessário entender mais sobre o território da UFRN, assim como suas áreas de risco.

Segundo dados fornecidos pela UFRN, o seu campus possui uma área de 123 hectares e 43.000 estudantes distribuídos em mais de 200 cursos de bacharelado e mestrado. Em 2017, a Diretoria de Segurança Patrimonial (DSP) do centro acadêmico afirmou, em entrevista para o jornal Tribuna Do Norte, que os casos de assaltos acontecem na UFRN apesar dos 360 profissionais contratados, 5 viaturas e 2.150 câmeras instaladas para suprir as necessidades de segurança dentro do campus (LIMA, 2017). De acordo com o DSP, os horários mais frequentes para a realização de crimes dentro do campus são, no período da tarde entre 13:00 às 14:30 e a noite, entre 19:00 às 21:00, segundo a Diretoria as áreas mais visadas pelos assaltantes são os pontos de ônibus dos setores 1,2 , e 4 . Abaixo, o mapa destaca as zonas e setores da universidade e as áreas de risco (Fig.3).

Figura 3 - Mapa da Universidade Federal do Rio Grande do Norte

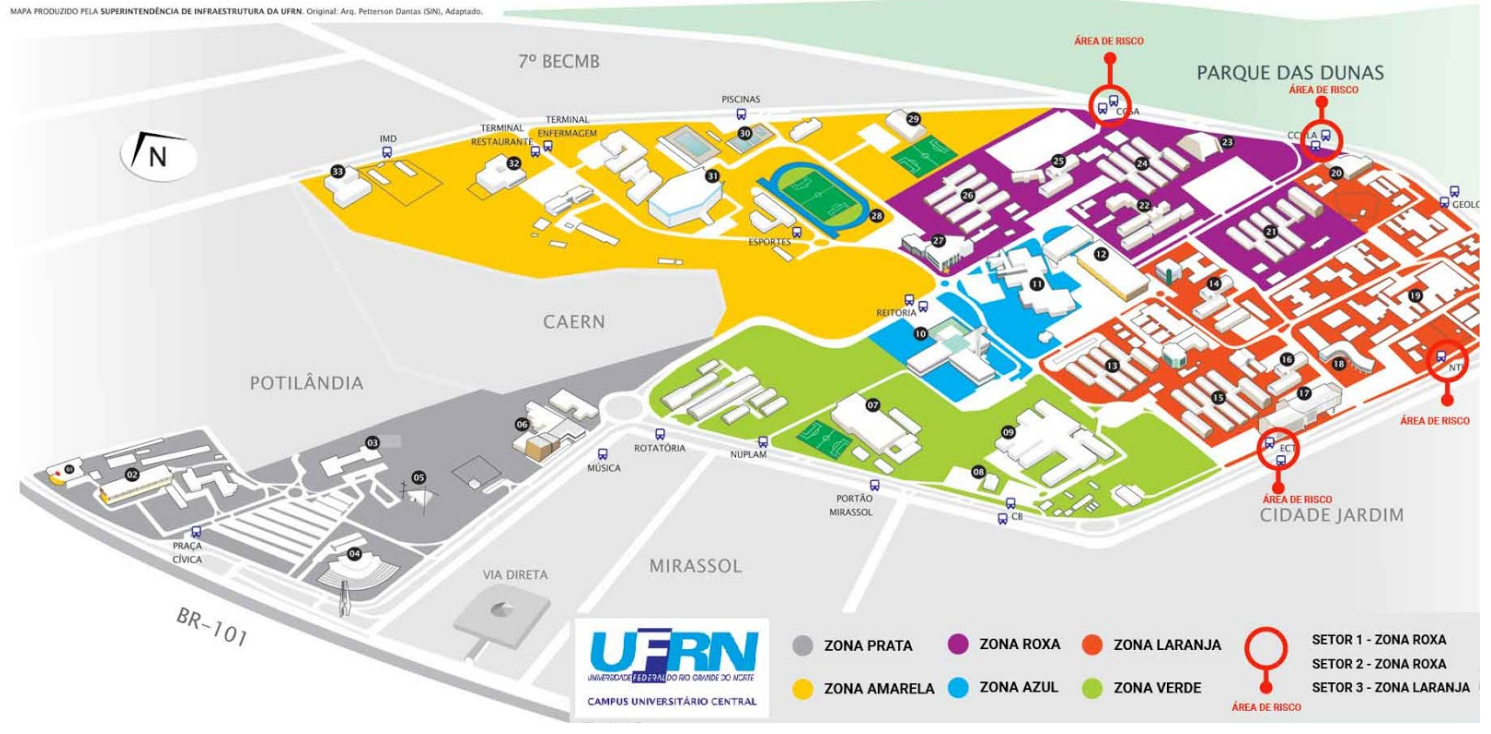

Fonte: Adaptado de UFRN (2018) 
Contudo, as legislações impostas à universidade limitam a atuação do setor de segurança da UFRN. A legislação não permite que a equipe de segurança da universidade atue no anel viário em torno do campus e $90 \%$ dos assaltos ocorrem fora da área de segurança determinada (LIMA, 2017).

Sabendo disso compreendemos que o VANT necessitaria cobrir uma área extensa, possuir autonomia de voo para ser solicitado por estudantes a qualquer horário de funcionamento da universidade, utilizar um sistema simples de decolagem que não necessite um grande número de funcionários para o seu funcionamento e por fim, que fosse seguro para os estudantes e representasse uma ameaça para os assaltantes. Através dessas informações foi possível definir 8 requisitos importantes para o desenvolvimento das propostas de solução. Os requisitos são:

- Prolongamento de bateria

- Autonomia

- VTOL (Vertical Landing Take Off)

- Sensores anticolisão

- Iluminação de identificação visual

- Peças modulares

- Estrutura de pequeno porte

- Utilização de frota por setor

\subsection{Propostas de soluções (Sketches)}

Nessa etapa foram desenvolvidos diversos sketches que levaram em consideração dados do briefing, informações coletadas e os requisitos estabelecidos. As imagens a seguir mostram o desenvolvimento da geração das propostas de soluções do projeto (Fig.4).

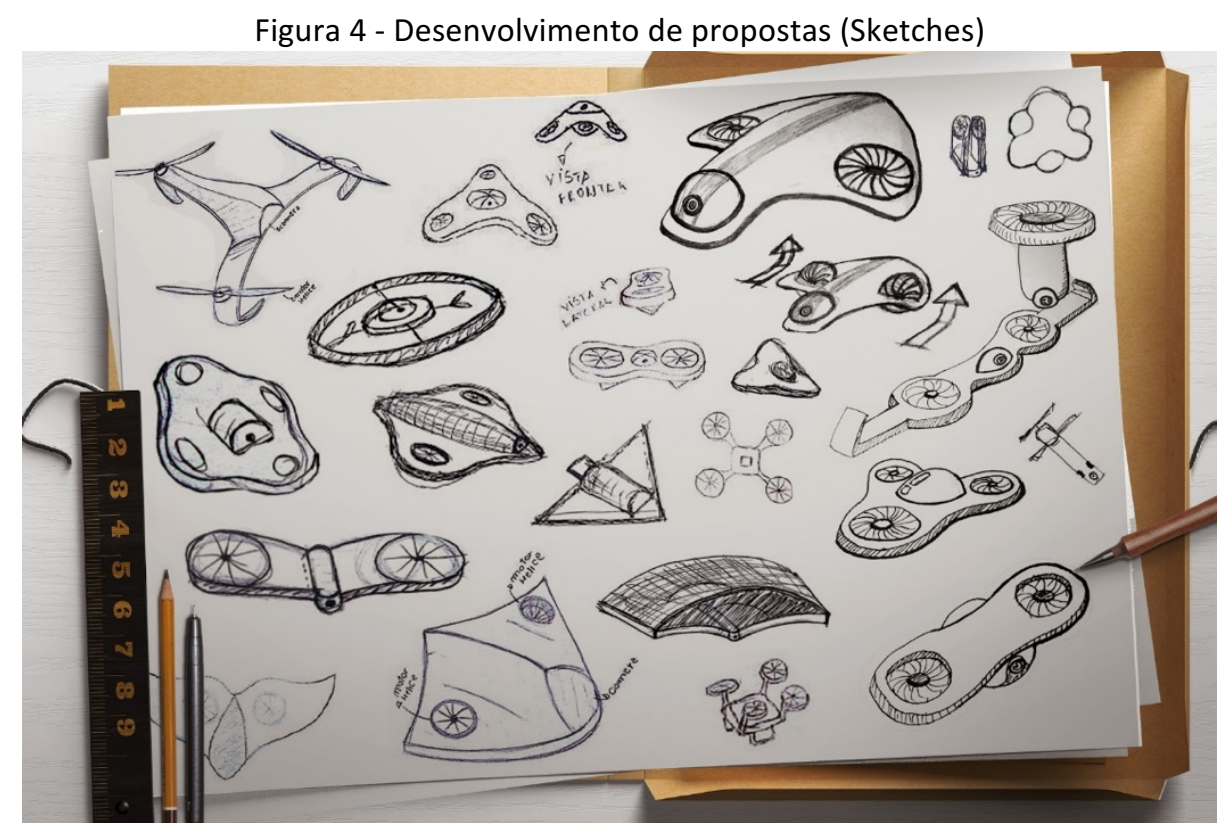

FONTE: Autores (2017) 
Foi utilizado vasta inspiração de aeronaves e OVNIs no estilo cyberpunk, movimento da ficção científica que mescla ciência avançada e a estética punk rock, para refletir aspectos ameaçadores e ostensivos em seu design, a fim de inibir as ações de bandidos.

Figura 5 - Proposta escolhida

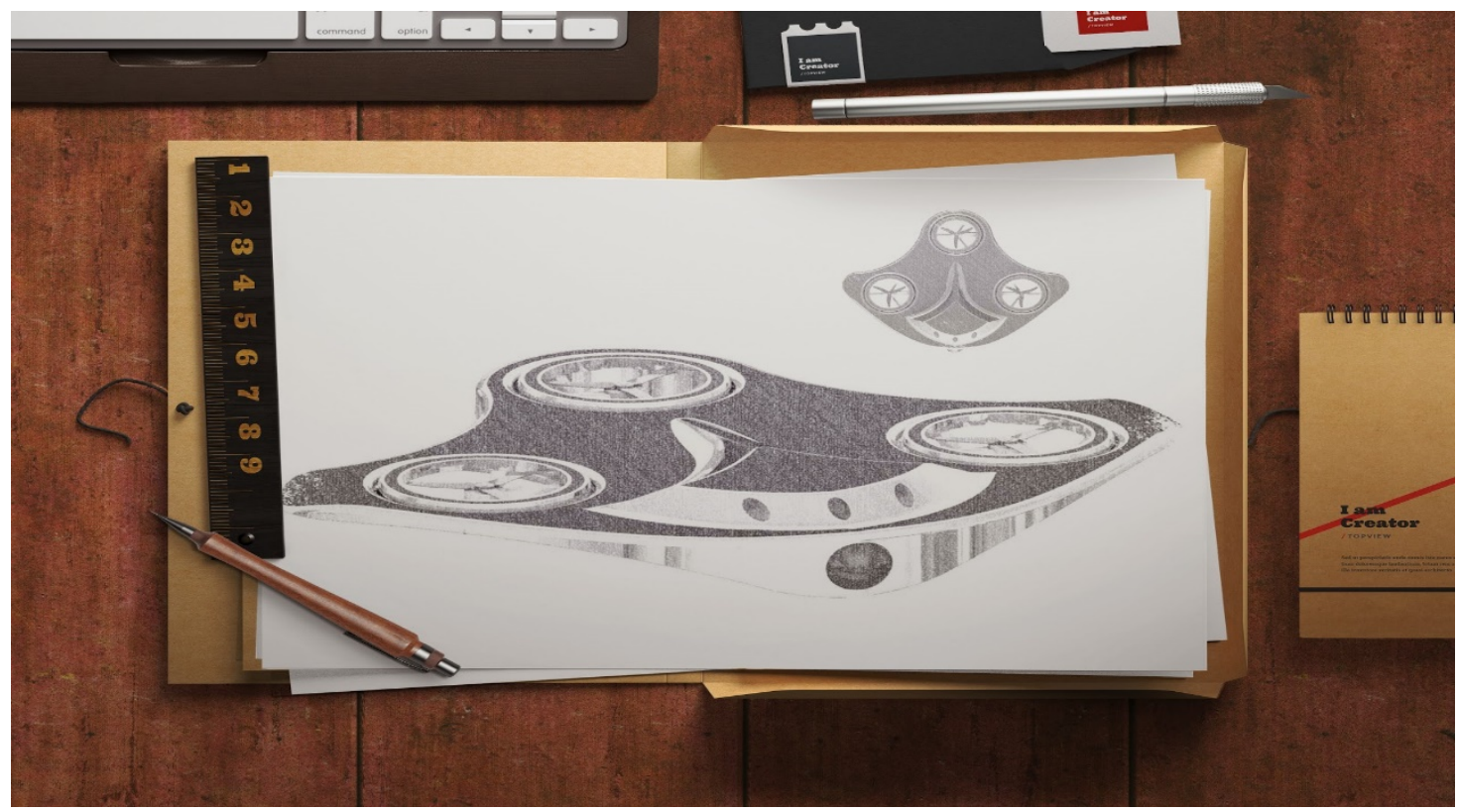

Fonte: Autores (2017)

Ao fim, a proposta escolhida, (Fig.5), se destacou das demais por se apresentar mais consistente e responder aos requisitos estabelecidos. Diferentemente da maioria dos drones no mercado esse possui 3 hélices, 2 dianteiras e 1 traseira que confere maior estabilidade. A escolha por fazer uso de peças modulares internas também foi um diferencial para o projeto já que um sistema modular facilita a troca e o reparo do drone em caso de desgaste. Em seu painel frontal o drone carrega uma câmera tipo FLIR, (Forward Looking Infrared), capaz de registrar imagens em alta qualidade, além de sensores contra choques físicos.

Com um design ameaçador e uma estrutura de pequeno porte, movida a bateria elétrica, faz-se necessário o uso de uma pequena frota de drones que irá atuar em zonas pré-definidas (Fig.4). Cada zona receberá 2 drones de segurança que só ficam ativos quando solicitados. Enquanto um drone for solicitado o outro ficaria em solo economizando bateria e, portanto, iriam alternar seus turnos de voos, garantindo a prolongação da bateria.

Além disso o resultado final também foi desenhado sob o conceito da biomimética, estudo focado na adaptação dos princípios da natureza à tecnologia (CAMARGO, et al., 2014). A biomimética tem sido um artifício bastante utilizado nos últimos anos por designer, arquitetos engenheiros e por projetistas em geral, uma vez que as fontes de inspirações são encontradas na natureza, onde há menor desperdício durante o ciclo de vida e onde tudo funciona como uma grande cadeia harmônica. Essa ciência contribui para a criação de artefatos mais eficientes e funcionais pois os projetistas encontram na natureza uma rica fonte de soluções consoante com a praticidade e sustentabilidade. Segundo Benyus (2012) a biomimética é uma nova ciência que 
estuda os modelos da natureza para imitar ou se inspirar em desenhos e processos biológicos para resolver problemas humanos. Nesse raciocínio optou-se por um desenho baseado na anatomia das arraias já que o seu formato elimina parte do arrasto e resistência aerodinâmica, além de aproveitar a própria resistência do ar para planar.

\subsection{Desenho técnico}

A partir das dimensões da câmera, tipo FLIR, solicitada no briefing foi elaborada uma prancha de desenho técnico do VANT com os diferentes detalhes e vistas necessárias para a elaboração da modelagem 3D e do protótipo (Fig.6).

Figura 6 - Desenho Técnico do VANT AEDES

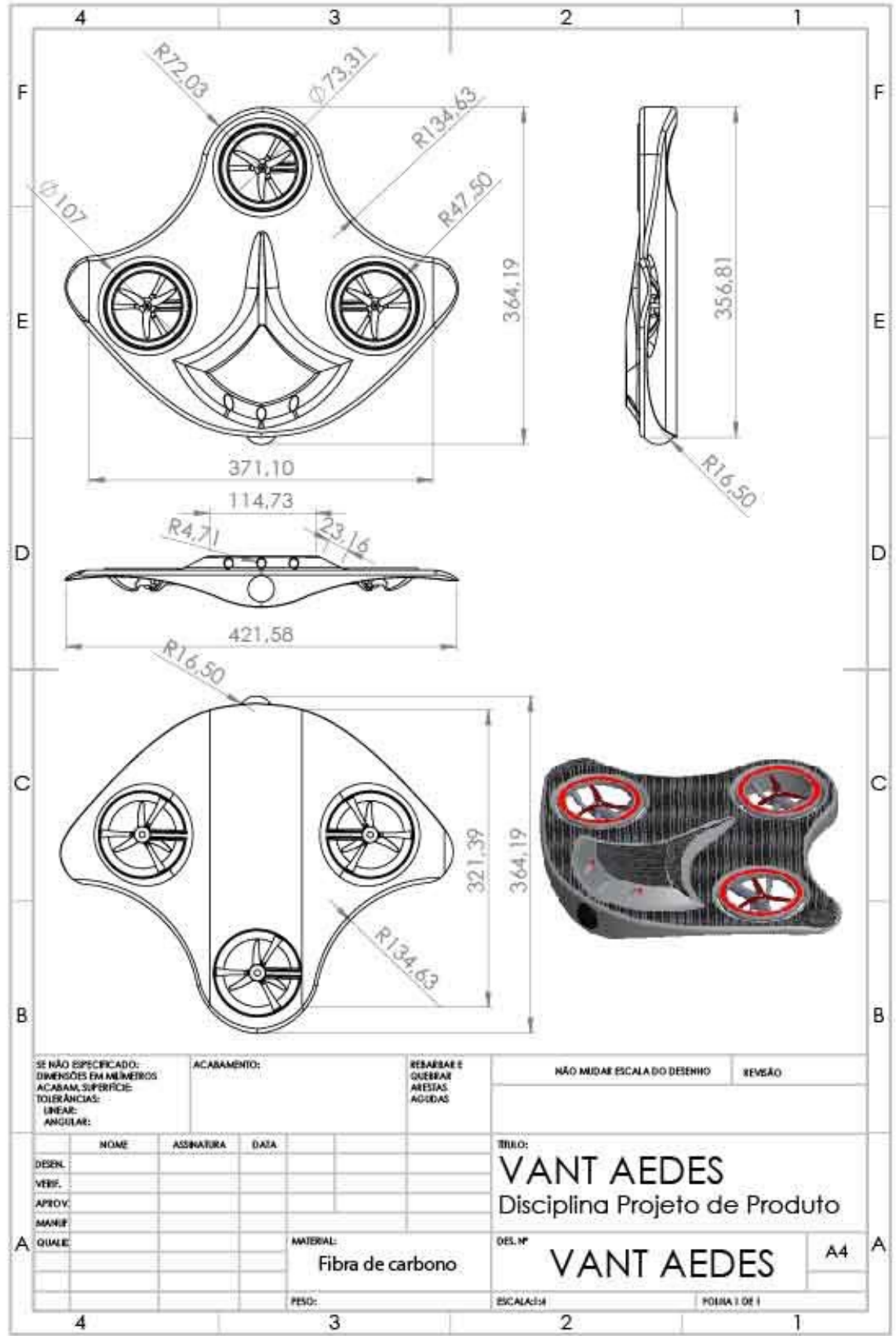




\section{Artigo Completo}

Fonte: Autores (2017)

\subsection{Modelagem 3D em software}

Como forma de melhor visualizar a proposta e identificar falhas no design foi desenvolvido um modelo 3D da proposta escolhida (Fig.7).

Figura 7 - Modelo 3D

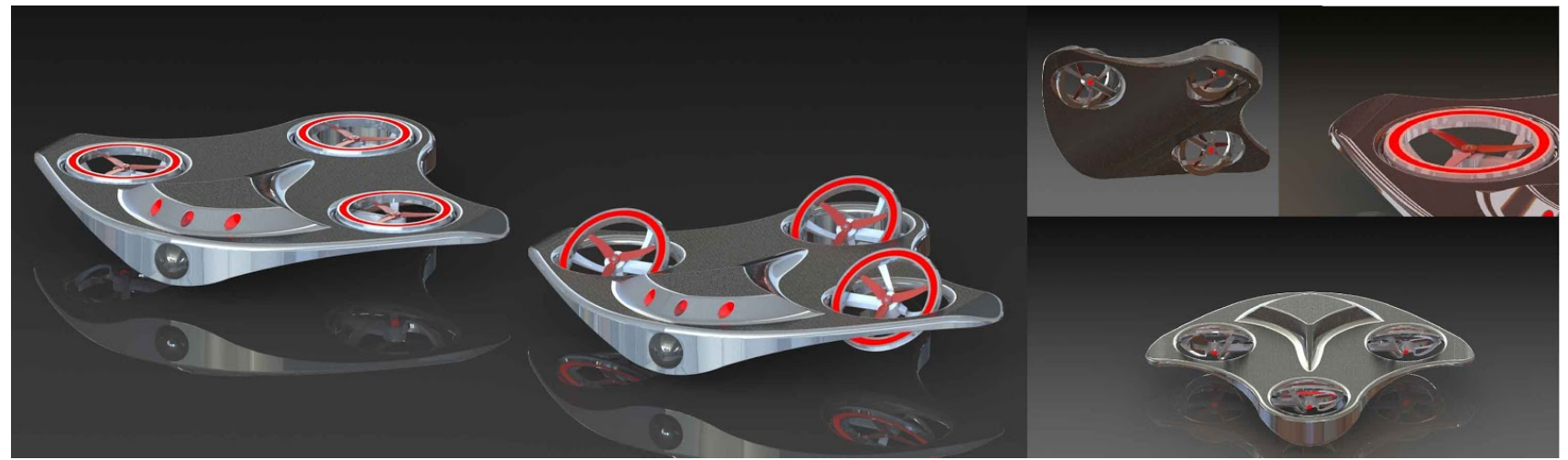

Fonte: Autores

\subsection{Flow Design (Túnel de vento virtual)}

Após a modelagem, o modelo tridimensional foi submetido à um túnel de vento virtual, utilizando o software Flow Design da AutoDesk (Fig.8). O estudo no túnel de vento se mostra importante uma vez que é possível a observação do comportamento do fluido gasoso sobre a aeronave, essa análise permite prever o escoamento laminar ou turbilhonado e consequentemente o ângulo máximo de estol (sustentação) da aeronave. Ultrapassado esse ângulo a sustentação diminui e o arrasto do veículo aumenta gradativamente, esse fenômeno é conhecido como "estol".

Figura 8 - Simulação túnel de vento virtual (Flow Design)

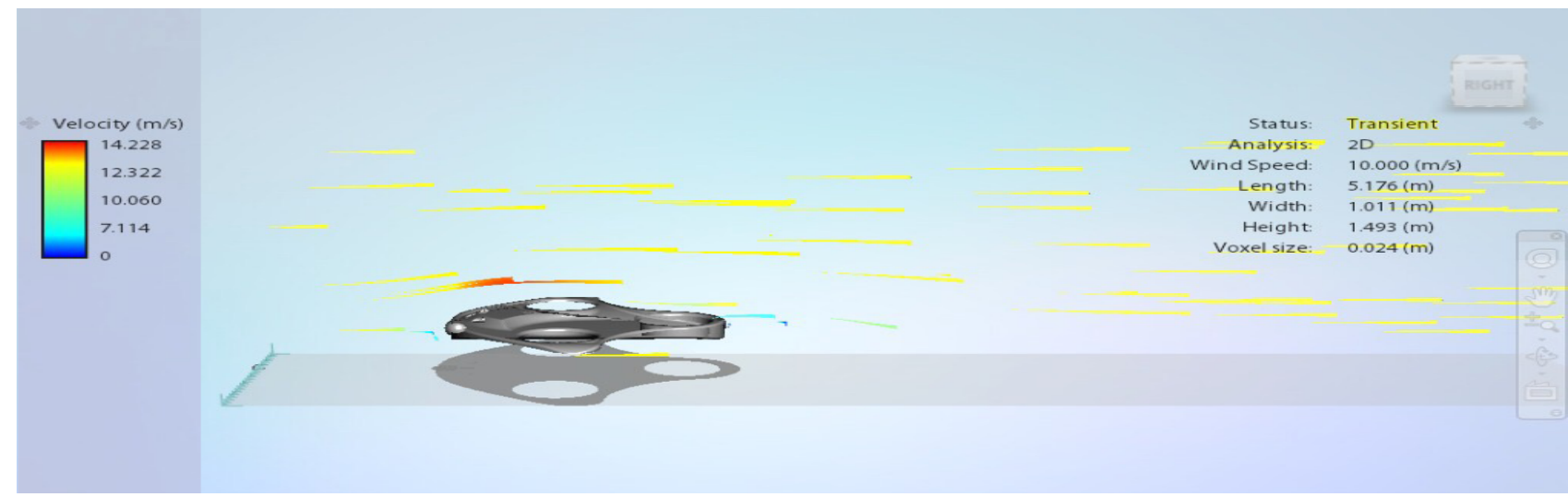

Fonte: Autores (2017) 


\subsection{Impressão 3D (Mini túnel de vento)}

A partir do desenvolvimento do modelo 3D virtual foi possível produzir um modelo físico em escala reduzida, com esse modelo foi possível testar o comportamento do vento sobre o artefato (Fig. 9). Foi construído um túnel de Venturi pelo professor e alunos da disciplina Projeto de Produto $\mathrm{V}$ (PP5).

Figura 9 - Túnel de vento com modelo impresso 3D

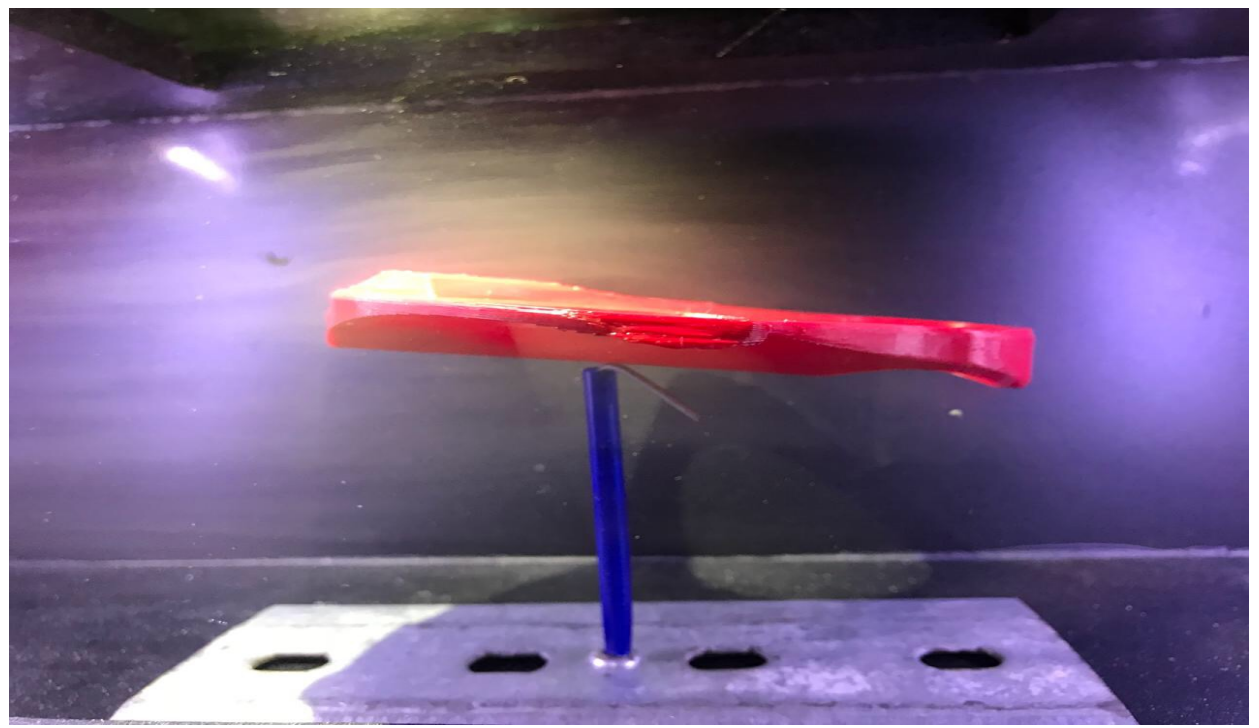

Fonte: Autores (2017)

\subsection{Prototipagem em escala (Isopor)}

Com o modelo 3D impresso e testado no túnel de Venturi, um modelo de isopor 1:1 (Fig.10), foi construído com o intuito de testar sua aerodinâmica e design em escala real. Essa etapa foi realizada com a ajuda da equipe Car-Kará Aerodesign que forneceram o uso de cortadores de isopor elétricos.

Figura 10 - Protótipo escala 1:1 em isopor 


\section{Artigo Completo}

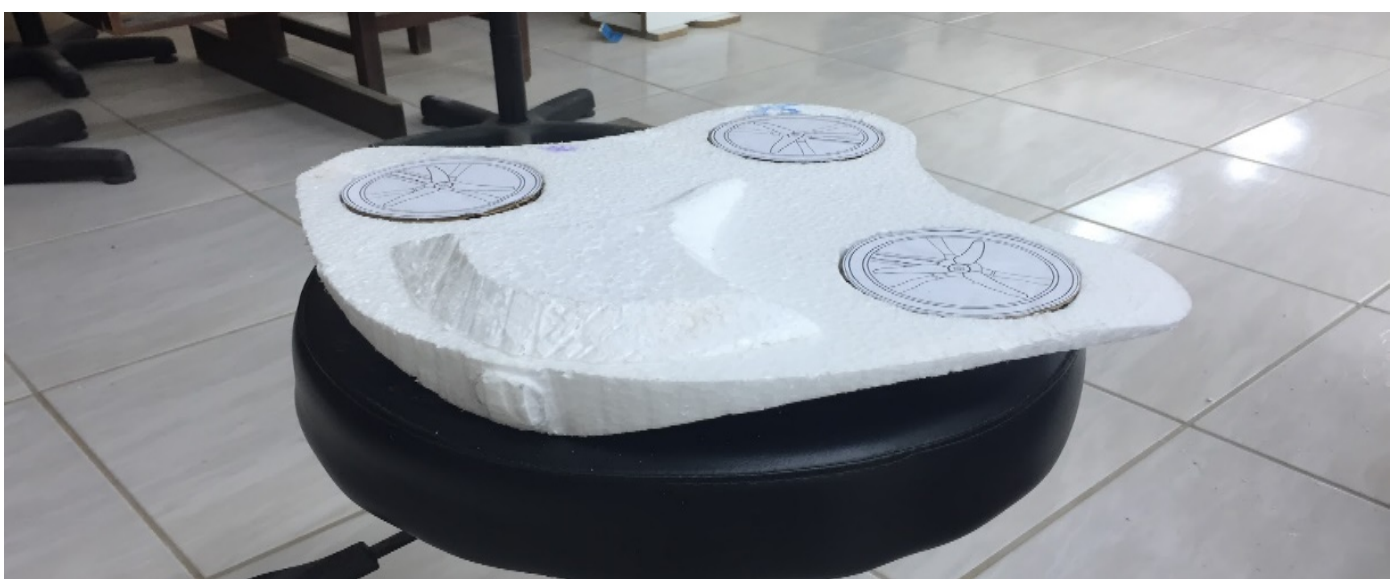

Fonte: Autores (2017)

\subsection{Exposição para especialistas}

Após a conclusão dos estudos, foi realizada uma apresentação na qual foi exposto o processo de criação e prototipação para convidados militares e civis (Fig.11). A exibição do projeto ocorreu no Departamento de Artes da UFRN, onde o curso design é ministrado.

Convidados como o Professor do ITA Paulo Gilberto Toro, o Professor da UFRN George Marinho e o Sargento Joelton (primeiro sargento da Força Aérea) visitaram a exposição e contribuíram com críticas e opiniões a respeito dos trabalhos.

Figura 11 - Exposição para especialistas

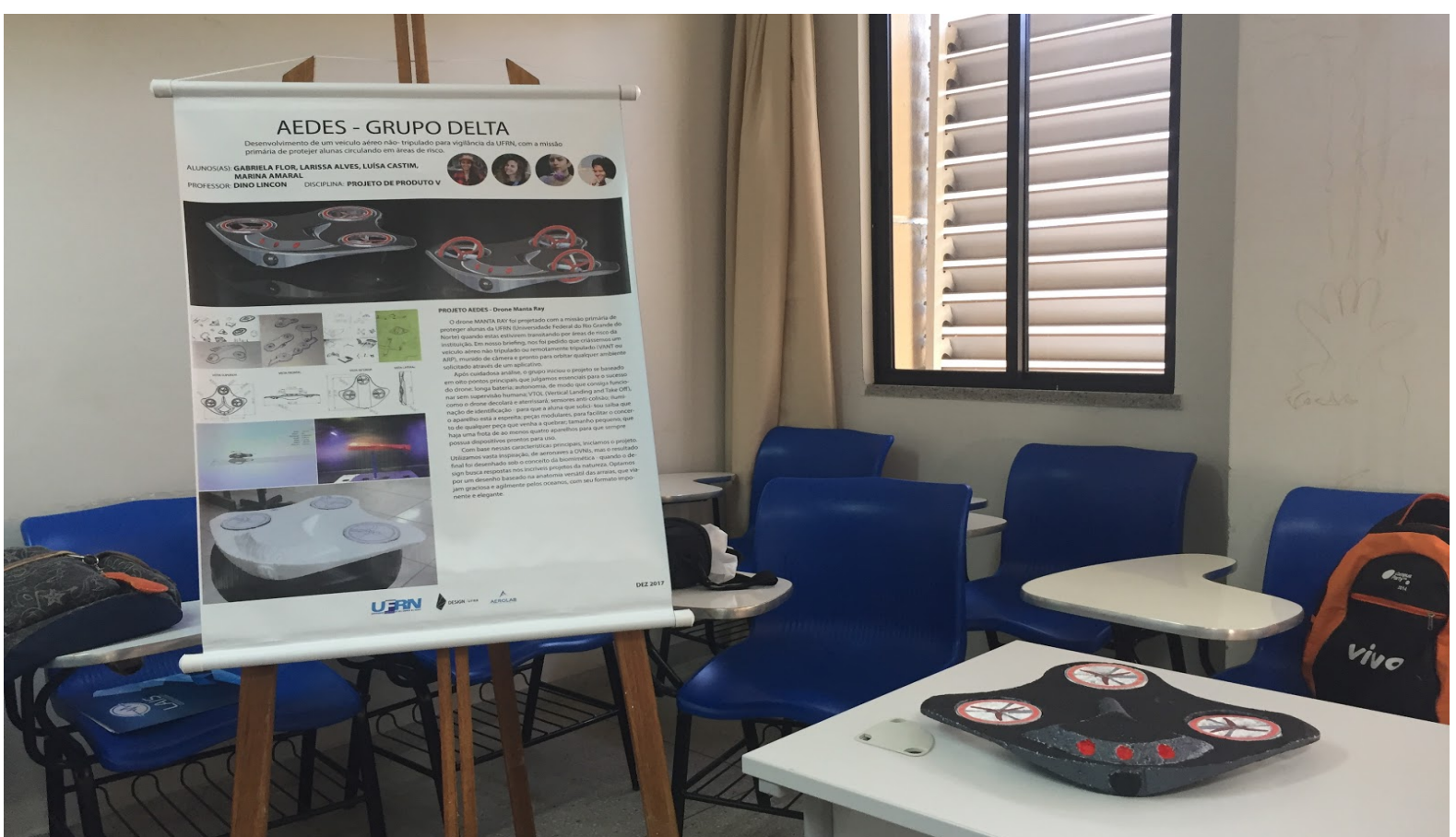

Fonte: Autores (2017)

\section{Resultados Finais}


Por fim, o design do VANT proposto possui uma estrutura de pequeno porte, feita em fibra de carbono e detalhes em alumínio. A sua configuração é composta por 2 motores frontais e um motor dianteiro conferindo maior estabilidade para a estrutura. O VANT proposto possui uma motorização totalmente elétrica, sendo alimentado por baterias e por isso possui a curta autonomia de 25 minutos. Portanto deve operar em frota de 2 aeronaves por zona da UFRN e decolar somente quando acionado - via aplicativo. Dessa forma pretende-se economizar energia e prolongar sua autonomia.

Através de uma câmera tipo FLIR o drone projetado pode capturar imagens em alta qualidade mesmo estando a algumas centenas de metros do "alvo". Os sensores instalados servem como medida de proteção contra choques físicos em alunos ou em árvores e obstáculos do campus.

Equipado com luzes de identificação tanto na vista frontal quanto na inferior, o VANT demonstra presença e proteção para as estudantes do campus. Por outro lado, o seu design ofensivo transmite uma ação de ameaça para possíveis agressores.

\section{Conclusão}

Com o processo de design aplicado ao projeto aeroespacial, foi possível conceber o projeto do VANT AEDES em um prazo de 3 meses, incluindo a etapa de estudos em ciência e tecnologia aeroespacial até a exposição do protótipo em escala 1/1 para especialistas. Isso demonstra a capacidade do design em aplicar ciência e tecnologia para soluções de problemas cotidianos da sociedade. Em particular, o problema de segurança pública enfrentado pelas alunas da UFRN, mas que pode ser dimensionado ao demais campus universitários brasileiros.

Ao fim dos estudos compreendeu-se que o uso de VANTs na segurança do espaço público surge como um elemento de reforço, que pode simplificar e executar as atividades de segurança com rapidez e eficiência. A sua inserção no setor de segurança da UFRN poderá inibir os bandidos e diminuir os casos de assalto no campus. É importante ressaltar o uso de VANTs como uma ferramenta de apoio à proteção e segurança pública, pois, o seu uso facilita e auxilia, mas não dispensa o trabalho de seguranças e policiais.

Acredita-se que através do resultado final desse projeto, casos de assédios tenderão a diminuir e as estudantes universitárias poderão percorrer o campus da UFRN com maior segurança e tranquilidade. A sensação de segurança poderá favorecer o ambiente universitário no âmbito social como também político.

\section{Desdobramentos}

Como continuação recomenda-se aprofundamento dos estudos acerca do projeto e o desenvolvimento de protótipos em material semelhante ao definido, assim como o estudo mecânico, elétrico e tecnológico. Também deve ser explorado em futuros trabalhos o desenvolvimento e aplicação de um aplicativo móvel que promova a interação entre as alunas da UFRN E O VANT.

\section{Referências}

AVON et al. Violência contra a mulher no ambiente universitário, 2015. Disponível em: <http://www.agenciapatriciagalvao.org.br/dossies/violencia/pesquisa/violencia-contra-a-mulher- 
no-ambiente-universitario-data-popularinstituto-avon-2015/>. Acesso em: 03 abr. 2018.

BENYUS JANINE. Biomimesis. Como la ciencia innova inspirándose en la naturaleza. Metatemas, 2012.

CAMARGO, Maytê Galvão Pereira de; Pelegrini, Alexandre Vieira; "BIOMIMETISMO APLICADO AO DESIGN SUSTENTÁVEL NO AMBIENTE CONSTRUÍDO - UMA REVISÃO BIBLIOGRÁFICA SISTEMÁTICA", p. 2102-2113. In: Anais do 11을 Congresso Brasileiro de Pesquisa e Desenvolvimento em Design [ Blucher Design Proceedings, v. 1, n. 4]. São Paulo: Blucher, 2014.

CENTRO DE LANÇAMENTO BARREIRA DO INFERNO. Missão, Visão e Valores. Disponível em: <http://www.clbi.cta.br/internet/index.php/missao-visao-e-valores>. Acesso em: 03 abr. 2018.

G1. Assaltos nas paradas de ônibus da UFRN preocupam alunos e servidores, 2015. Disponível em: <http://g1.globo.com/rn/rio-grande-do-norte/noticia/2015/03/assaltos-nas-paradas-de-onibusda-ufrn-preocupam-alunos-e-servidores.html>. Acesso em: 03 abr.2018.

GALVÃO, Márcio Régis. Drones na Segurança Pública, 2017. Disponível em: <http://www.administradores.com.br/artigos/tecnologia/drones-na-seguranca-publica/105745/>. Acesso em: 03 abr. 2018.

LIMA. Campus registra 21 assaltos este ano, 2017. Disponível em: <http://www.tribunadonorte.com.br/noticia/campus-registra-21-assaltos-este-ano/378434>. Acesso em: 02 abr. 2018.

MACARRÃO, L. Importância do uso de Mock-ups e de técnicas de prototipagem rápida e ferramental rápido nos processos de desenvolvimento de produtos na indústria automotiva. São Paulo, Tese de Mestrado USP, 2007

MILESKI, André M. Uma história de alta tecnologia. Revista Tecnologia e Defesa, [S.I.] ano 20, n. 92, p. 42-61, 2007.

PREFEITURA DE SP. Dronepol, 2017. Disponível em: <http://www.prefeitura.sp.gov.br/cidade/secretarias/seguranca_urbana/noticias/?p=238299>. Acesso em: 02 abr. 2018.

SILVA NETO, Augusto Severo da. Polícia no ar: uma visão do emprego de helicópteros na manutenção da ordem pública. In: O Alferes, Belo Horizonte, ano 4, n. 9, p. 125-164, 1986.

SILVEIRA. Onda de assaltos perto de universidades assusta estudantes em São Carlos, SP, 2017. Disponível em: <https://g1.globo.com/sp/sao-carlos-regiao/noticia/onda-de-assaltos-perto-deuniversidades-assusta-estudantes-em-sao-carlos-sp.ghtml>. Acesso em: 02 abr. 2018.

UFRN. Sobre a UFRN, 2017. Disponível em: <http://www.ufrn.br/institucional/sobre-a-ufrn>. Acesso em: 02 abr. 2018. 